\title{
Thermoelectric properties of In and I doped PbTe
}

Ashoka Bali, Raju Chetty, Amit Sharma, Gerda Rogl, Patrick Heinrich, Satyam Suwas, Dinesh Kumar Misra,

Peter Rogl, Ernst Bauer, and Ramesh Chandra Mallik'

Citation: J. Appl. Phys. 120, 175101 (2016); doi: 10.1063/1.4965865

View online: http://dx.doi.org/10.1063/1.4965865

View Table of Contents: http://aip.scitation.org/toc/jap/120/17

Published by the American Institute of Physics

\section{Articles you may be interested in}

High thermoelectric potential of n-type Pb1-xTixTe alloys

J. Appl. Phys. 120, 055104055104 (2016); 10.1063/1.4960573

\section{AlP $\left.\right|_{\text {Applied Physics }} ^{\substack{\text { Journal of } \\ \text { Ans }}}$}

INTRODUCING INVITED PERSPECTIVES

Ultrafast magnetism and THz spintronics

Authors: Jakob Walowski and Markus Münzenberg 


\title{
Thermoelectric properties of In and I doped PbTe
}

\author{
Ashoka Bali, ${ }^{1}$ Raju Chetty, ${ }^{1}$ Amit Sharma, ${ }^{2}$ Gerda Rogl,${ }^{3,4,5}$ Patrick Heinrich, ${ }^{5}$ \\ Satyam Suwas, ${ }^{2}$ Dinesh Kumar Misra, ${ }^{6}$ Peter Rogl, ${ }^{3}$ Ernst Bauer, ${ }^{4,5}$ \\ and Ramesh Chandra Mallik ${ }^{1, a)}$ \\ ${ }^{1}$ Thermoelectric Materials and Devices Laboratory, Department of Physics, Indian Institute of Science, \\ Bangalore 560012, India \\ ${ }^{2}$ Department of Materials Engineering, Indian Institute of Science, Bangalore 560012, India \\ ${ }^{3}$ Institute of Materials Chemistry and Research, University of Vienna, Währingerstrasse 42, Wien, Austria \\ ${ }^{4}$ Christian Doppler Laboratory for Thermoelectricity, Wiedner Hauptstrasse 8-10, A-1040 Wien, Austria \\ ${ }^{5}$ Institute of Solid State Physics, TU-Wien, Wiedner Hauptstrasse, 8-10, A-1040, Wien, Austria \\ ${ }^{6}$ Physics of Energy Harvesting Division, CSIR-National Physical Laboratory, Dr. K.S. Krishnan Marg, \\ New Delhi 110012, India
}

(Received 11 August 2016; accepted 8 October 2016; published online 1 November 2016)

\begin{abstract}
A systematic study of structural, microstructural, and thermoelectric properties of bulk PbTe doped with indium (In) alone and co-doped with both indium and iodine (I) has been done. X-ray diffraction results showed all the samples to be of single phase. Scanning electron microscopy (SEM) results revealed the particle sizes to be in the range of micrometers, while high resolution transmission electron microscopy was used to investigate distinct microstructural features such as interfaces, grain boundaries, and strain field domains. Hall measurement at $300 \mathrm{~K}$ revealed the carrier concentration $\sim 10^{19} \mathrm{~cm}^{-3}$ showing the degenerate nature which was further seen in the electrical resistivity of samples, which increased with rising temperature. Seebeck coefficient indicated that all samples were n-type semiconductors with electrons as the majority carriers throughout the temperature range. A maximum power factor $\sim 25 \mu \mathrm{W} \mathrm{cm} \mathrm{cm}^{-1} \mathrm{~K}^{-2}$ for all In doped samples and $\mathrm{Pb}_{0.998} \mathrm{In}_{0.003} \mathrm{Te}_{1.000} \mathrm{I}_{0.003}$ was observed at $700 \mathrm{~K}$. Doping leads to a reduction in the total thermal conductivity due to enhanced phonon scattering by mass fluctuations and distinct microstructure features such as interfaces, grain boundaries, and strain field domains. The highest $z \mathrm{~T}$ of 1.12 at $773 \mathrm{~K}$ for In doped samples and a $z \mathrm{~T}$ of 1.1 at $770 \mathrm{~K}$ for In and I co-doped samples were obtained. Published by AIP Publishing. [http://dx.doi.org/10.1063/1.4965865]
\end{abstract}

\section{INTRODUCTION}

In today's world, there is a renewed interest in the search for alternative sources of energy. There are several potential alternative sources among which thermoelectricity (TE) holds an important place due to the ability of thermoelectric materials to convert heat directly into electricity, and vice - versa. Some of the advantages of thermoelectric generators in comparison to other sources are their noiseless operation, no environmental pollution, absence of any moving parts resulting in their robustness and a longer life span. The thermoelectric conversion efficiency depends on a factor known as the dimensionless "figure of merit" $(z T)$, which is defined by $z \mathrm{~T}=\mathrm{S}^{2} \mathrm{~T} / \rho \kappa_{\mathrm{T}}$, where $\mathrm{S}$ is the Seebeck coefficient, $\rho$ the electrical resistivity and $\kappa_{\mathrm{T}}$ is total thermal conductivity $\left(\kappa_{\mathrm{T}}=\kappa_{\mathrm{e}}+\kappa_{\mathrm{l}}\right.$, with $\kappa_{\mathrm{e}}$ being the electronic part and $\kappa_{\mathrm{l}}$ the lattice contribution). A $z \mathrm{~T}$ of $\sim 3$ is required for thermoelectric materials to be equal in efficiency to other commercial sources of energy. Lead telluride ( $\mathrm{PbTe}$ ) based systems belong to group IV-VI and are one of the well-known materials, which can be operated in the temperature range from $350 \mathrm{~K}$ to $850 \mathrm{~K}$. The thermoelectric figure of merit, achieved by undoped $\mathrm{PbTe}$, is usually about $\sim 0.8$ at $750 \mathrm{~K}$, which is

\footnotetext{
a) Author to whom correspondence should be addressed. Electronic mail: rcmallik@physics.iisc.ernet.in
}

much below the desired $z \mathrm{~T}$ of 3 , and hence, needs to be increased. In order to do so, the power factor $\left(\mathrm{S}^{2} / \rho\right)$ must be increased while simultaneously a reduction of the total thermal conductivity $\left(\kappa_{\mathrm{T}}\right)$ is necessary. In practice, $\kappa_{1}$ is a lattice property, while $\mathrm{S}, \rho$, and $\kappa_{\mathrm{e}}$ are electronic properties depending on the carrier concentration of the material, and hence, are correlated to each other. An increase of the carrier concentration leads to a decrease of the Seebeck coefficient and $\rho$ but also to a higher $\kappa_{\mathrm{e}}$. Therefore, optimising the carrier concentration is very important ${ }^{1}$ for obtaining the best power factor, which can be done through doping. For $\mathrm{PbTe}$, several methods have been adopted in the past to increase $z$ T. Band structure engineering by alloying with a suitable element is one of them. ${ }^{2}$ Distortion of the electronic density of states near the Fermi level by doping PbTe with thallium has been observed yielding a $z$ T of 1.5 at $773 \mathrm{~K}$ (Ref. 3) due to an increased Seebeck coefficient and a decreased thermal conductivity. This improvement in the Seebeck coefficient was explained by the Mahan-Sofo theory ${ }^{4}$ in which a delta function shaped energy distribution of electrons taking part in the transport results in a maximum thermoelectric efficiency. More recently, it has been shown that breaking of crystal symmetry by chemical doping opens up the bulk band gap, resulting in a $z \mathrm{~T}$ of 1 in both $\mathrm{Pb}_{0.58} \mathrm{Sn}_{0.40} \mathrm{Na}_{0.02} \mathrm{Te}_{1.00}$ at $856 \mathrm{~K}$ (Ref. 5) and in $\mathrm{Pb}_{0.56} \mathrm{~K}_{0.04} \mathrm{Sn}_{0.4} \mathrm{Te}_{1.00}$ at $708 \mathrm{~K}$. ${ }^{6}$ The second approach has been to embed nanoscale inclusions 
inside the bulk PbTe matrix. Through this approach $2 \mathrm{~mol}$. \% $\mathrm{SrTe}$, embedded in PbTe matrix, resulted in a zT of 1.7 at $815 \mathrm{~K}$ (Ref. 7) and a further enhancement of $z \mathrm{~T}$ up to 2.2 at $915 \mathrm{~K}$ was achieved for p-type PbTe by having endotaxial nanostructures of $4 \mathrm{~mol}$. \% SrTe along with powder processing and spark plasma sintering methods. ${ }^{8}$ Bulk nanostructured LAST (Lead-Antimony-Silver-Telluride) and TAGS (Tellurium-Antimony-Germanium-Silver) are another category of compounds ${ }^{9}$ which have shown high $z$ Ts for many compositions. ${ }^{10}$ One method to look at the thermoelectric figure of merit of $\mathrm{PbTe}$ is through the material parameter $(\beta)$, which is related to $\mathrm{zT}$ by

$$
z T=\frac{\left[\eta-\left(r+\frac{5}{2}\right)\right]^{2}}{(\beta \exp (\eta))^{-1}+\left(r+\frac{5}{2}\right)},
$$

where $\eta\left(=\mathrm{E}_{\mathrm{F}} / \mathrm{k}_{\mathrm{B}} \mathrm{T}\right)$ is the reduced Fermi energy, $\mathrm{r}$ the scattering parameter which can take the values $-1 / 2$ for acoustic lattice scattering, $1 / 2$ for optical phonon scattering and $3 / 2$ for ionised impurity scattering. $\beta$ is the material parameter given by

$$
\beta=\left(\frac{k_{B}}{e}\right)^{2} \frac{(2 e \mu)}{\kappa_{l}}\left(\frac{2 \pi m^{*} k_{B} T}{h^{2}}\right)^{3 / 2} T .
$$

Here $\mu$ is the mobility, $\mathrm{k}_{\mathrm{B}}$ is the Boltzmann constant, $\mathrm{e}$ is the electronic charge, $\kappa_{1}$ is the lattice thermal conductivity, $h$ is the Planck's constant, and $m^{*}$ is the density of states effective mass. $\mathrm{m}^{*}=N_{v}^{2 / 3}\left(m^{* 2} m^{*} \|\right)^{1 / 3}$ where $\mathrm{N}_{\mathrm{v}}$ is the band degeneracy and $\mathrm{m}^{*}{ }_{\perp}$ and $\mathrm{m}^{*} \|$ are effective masses in the transverse and longitudinal directions, respectively. All the above properties, except $\kappa_{1}$, are dependent on the carrier concentration. Hence, $\beta$, and therefore, $z \mathrm{~T}$ can be increased by doping which will reduce $\kappa_{1}$ by mass fluctuation scattering and simultaneously increase $\mathrm{N}_{\mathrm{v}}{ }^{11,12}$ along with $\mu \mathrm{m}^{*^{(3 / 2)}}$. Additionally, it has been predicted that it is possible to obtain a high power factor if the Fermi level is located (i) near the bottom of a heavy mass valley ${ }^{13}$ and (ii) $\sim 2 \mathrm{k}_{\mathrm{B}} \mathrm{T}$ inside the band edge of the valence or conduction band for a $\mathrm{p}$ or $\mathrm{n}$ type material so that the carriers with higher energy will contribute to the transport. ${ }^{14}$ All of the above criteria can be satisfied by a proper choice of dopants.

For this purpose, indium and iodine come across as good candidates satisfying the above criteria. Indium (In) is known as an n-type dopant in PbTe. Indium forms a deep defect state localised near the bottom of the conduction band in $\mathrm{PbTe},{ }^{15,16}$ and the Fermi level pinning occurs in several lead telluride based compounds ${ }^{17,18}$ doped with group III elements, which leads to a very less variation of the Seebeck coefficient $(\sim 50 \mu \mathrm{V} / \mathrm{K})$ over the entire measurement temperature range. ${ }^{19}$ Thermoelectric materials generally show a peak $z \mathrm{~T}$ for a particular temperature and dopant concentration, thereby limiting their application in practical commercial devices, which typically require an operation over a large temperature range. Second, the difference in the sizes of In and $\mathrm{Pb}$ could lead to mass fluctuation scattering, which can reduce $\kappa_{1}$. Third, Tl, which belongs to the same group as indium, forms resonant states in $\mathrm{PbTe}^{3}$ It would be interesting to systematically evaluate a similar phenomenon for indium. On the other hand, iodine belongs to group VII and is a very good n-type dopant in $\mathrm{PbTe}$ as it gives one electron for each atom, which leads to a $z \mathrm{~T}$ of 1.4 at $800 \mathrm{~K}^{20}$ Therefore, it will be interesting to dope $\mathrm{PbTe}$ with both indium and iodine together so that a stability of properties is achieved along with a simultaneous proper control of the carrier concentration. Thus, indium can possibly lead to stability over a large range of the composition, while iodine can control the composition. Iodine doped PbTe was studied by Pei et $a l^{20}$ achieving a $z \mathrm{~T}$ of 1.4 at $700 \mathrm{~K}$. Indium doping was done in $\mathrm{PbSe}_{1-\mathrm{y}} \mathrm{Te}_{\mathrm{y}}$ which yielded a $z \mathrm{~T}$ of 0.66 at $800 \mathrm{~K}^{21}$ Two phase PbTe with indium secondary phase resulted in a zT of 0.78 at $723 \mathrm{~K}^{22}$ Previously, indium and iodine codoping has been attempted by Guch et al. ${ }^{23}$ who have achieved a $z \mathrm{~T}$ of 0.45 at $600 \mathrm{~K}$ (Ref. 19) and 0.61 at $655 \mathrm{~K},{ }^{23}$ respectively. Long et al. ${ }^{24}$ obtained a peak $z \mathrm{~T}$ of 1.15 at $666 \mathrm{~K}$ for 0.10 wt. $\%$. $\mathrm{PbI}_{2}$ and 0.3 at. \% In doping; however, no correlation with the microstructure was reported. The merit of the present work lies in the fact that a systematic study of In and I doping in PbTe has been pursued here along with microstructure and transmission electron microscope (TEM) characterisation with an aim to understand the underlying physics. Furthermore, the sample synthesis was repeated three times, which showed the reproducibility of the results. In the present work, two series of doped PbTe have been synthesised and a systematic study of thermoelectric properties has been performed. In the first series, PbTe has been doped only by indium (In), i.e., $\mathrm{Pb}_{(1.001-\mathrm{x})} \mathrm{Te}_{1.000} \mathrm{In}_{\mathrm{x}}$, where $\mathrm{x}=0.001,0.002,0.003$, and 0.004, named PIN-1, PIN-2, PIN-3, and PIN-4, respectively. Extra Pb has been added so as to keep the intrinsic carrier density at a minimum because the solubility of $\mathrm{Pb}$ in $\mathrm{PbTe}$ is $<1$ at. \%. ${ }^{25}$ Samples of the other series were co-doped by indium and iodine (I), i.e., $\mathrm{Pb}_{0.998} \mathrm{In}_{0.003} \mathrm{Te}_{1.000} \mathrm{I}_{\mathrm{x}}$, where $\mathrm{x}=0.001,0.002,0.003$, and 0.004, named as PINI-1, PINI-2, PINI-3, and PINI-4, respectively.

\section{EXPERIMENTAL DETAILS}

Two series of the PbTe with the chemical formulae $\mathrm{Pb}_{(1.001-\mathrm{x})} \mathrm{Te}_{1.000} \mathrm{In}_{\mathrm{x}}(\mathrm{x}=0.001,0.002,0.003$, and 0.004$)$ and $\mathrm{Pb}_{0.998} \mathrm{In}_{0.003} \mathrm{Te}_{1.000} \mathrm{I}_{\mathrm{x}}(\mathrm{x}=0.001,0.002,0.003$, and 0.004$)$ were prepared using high purity $\mathrm{Pb}(99.9 \%), \mathrm{Te}(99.999 \%)$, $\mathrm{In}(99.99 \%)$, and $\mathrm{PbI}_{2}$. The synthesis was carried out in two steps. First, big batches of the end compositions $\mathrm{Pb}_{1.001} \mathrm{Te}_{1.000}$ and $\mathrm{Pb}_{0.997} \mathrm{Te}_{1.000} \mathrm{In}_{0.004}$ were synthesised and in the second step, these compounds were mixed in proper weight ratios to obtain the compositions for the PIN series between these end members. A similar procedure was followed for the indium and iodine codoped samples (PINI series). For the synthesis of the end compositions, the elements were mixed in appropriate stoichiometric ratios and sealed under $\sim 10^{-2} \mathrm{~Pa}$ vacuum in carbon coated quartz tubes. These samples were slowly heated up to $1273 \mathrm{~K}$ in $10 \mathrm{~h}$ and kept at that temperature for $6 \mathrm{~h}$, followed by quenching in water. The samples were then annealed at $973 \mathrm{~K}$ for $72 \mathrm{~h}$, followed again by water quenching. The prepared ingots were subjected to hand grinding with a mortar 
and pestle to obtain a fine powder, which was then compacted into cylindrical pellets by hot pressing under vacuum $\sim 10^{-3} \mathrm{~Pa}$ at $913 \mathrm{~K}$ with $30 \mathrm{MPa}$ pressure for $30 \mathrm{~min}$. All the pellets had more than $95 \%$ of the theoretical density $(8.24 \mathrm{~g} /$ $\mathrm{cm}^{3}$ ). The hot pressed pellets were cut into rectangular pieces with dimensions of $3 \mathrm{~mm} \times 3 \mathrm{~mm} \times 10 \mathrm{~mm}$ for resistivity and Seebeck measurements, and cylindrical pellets of $0.5 \mathrm{~mm}$ thickness and $6 \mathrm{~mm}$ diameter for thermal diffusivity measurements.

Phase identification of the prepared samples was performed via a Bruker D8 Advance with $\mathrm{Cu} \mathrm{K}_{\alpha}$ radiation and scan speed of $2 \% \mathrm{~min}$. Backscattered electron images (BSEs) were taken with Quanta 200 environmental scanning electron microscope (ESEM). Compositional analysis was carried out on JEOL JXA-8530F Electron Probe Micro Analyzer (EPMA) with Wavelength Dispersive Spectroscopy (WDS) detectors. The carrier concentration was measured at room temperature using a home built set-up under a magnetic field of $0.5 \mathrm{~T}$. Temperature dependent Seebeck coefficient and electrical resistivity were measured using a LINSEIS LSR-3 apparatus. The thermal conductivity was measured by the laser flash method using a Flashline 3000 (ANTER). The finer microstructural details of the samples were obtained by performing Bright field (BF) and Dark field (DF) imaging using an FEI Tecnai F-30 transmission electron microscope (TEM) equipped with a field emission source at $300 \mathrm{kV}$ operating voltage. Selected area electron diffraction (SAED) and high-resolution transmission electron microscopy (HRTEM) experiments have been performed to further analyse the change in structure of PbTe with different elemental doping. The samples for TEM were prepared by the drop cast method in which the sample powder was suspended in toluene and left to dry under IR radiation till the solvent evaporated.

\section{RESULTS AND DISCUSSION}

\section{A. Structure}

The X-Ray diffraction patterns of both the series showed sharp peaks which indicated the polycrystalline nature of the samples. PIN samples did not show any secondary phase peak, indicating single-phase compounds; however, the samples PINI-1 and PINI-2 showed a trace of $\mathrm{Pb}$ as secondary phase (inset (c) of Figure 1). Although Rietveld refinement was carried out for all samples, Figure 1 exemplarily shows the refined powder patterns for the samples PIN-1 and PINI3 , respectively. Lattice parameters, $a$, evaluated from Rietveld refinement for all the compounds are shown in Figure 2.

The lattice constant of undoped PbTe is $6.4556 \AA$. In case of the PIN series, $a$ slightly increases with increasing dopant content, contrary to the expected trend (i.e., $a$ should decrease with In dopant, because in PbTe indium is believed to substitute at the $\mathrm{Pb}$ site and exists in $\mathrm{a}+3$ state $\left(\mathrm{In}^{3+}\right)$ for which the Pauling radii is $94 \mathrm{pm}$, which is smaller than that of $\mathrm{Pb}^{2+}(133 \mathrm{pm})$. The reason for this unusual behaviour could be the addition of excess $\mathrm{Pb}$ and/or non- stoichiometry. For the PINI samples, where both In and I were added, the situation is less complex as additional $\mathrm{I}^{-}$(radius $206 \mathrm{pm}$ ) is expected to substitute at the Te site, and the radius of $\mathrm{Te}^{2-}$
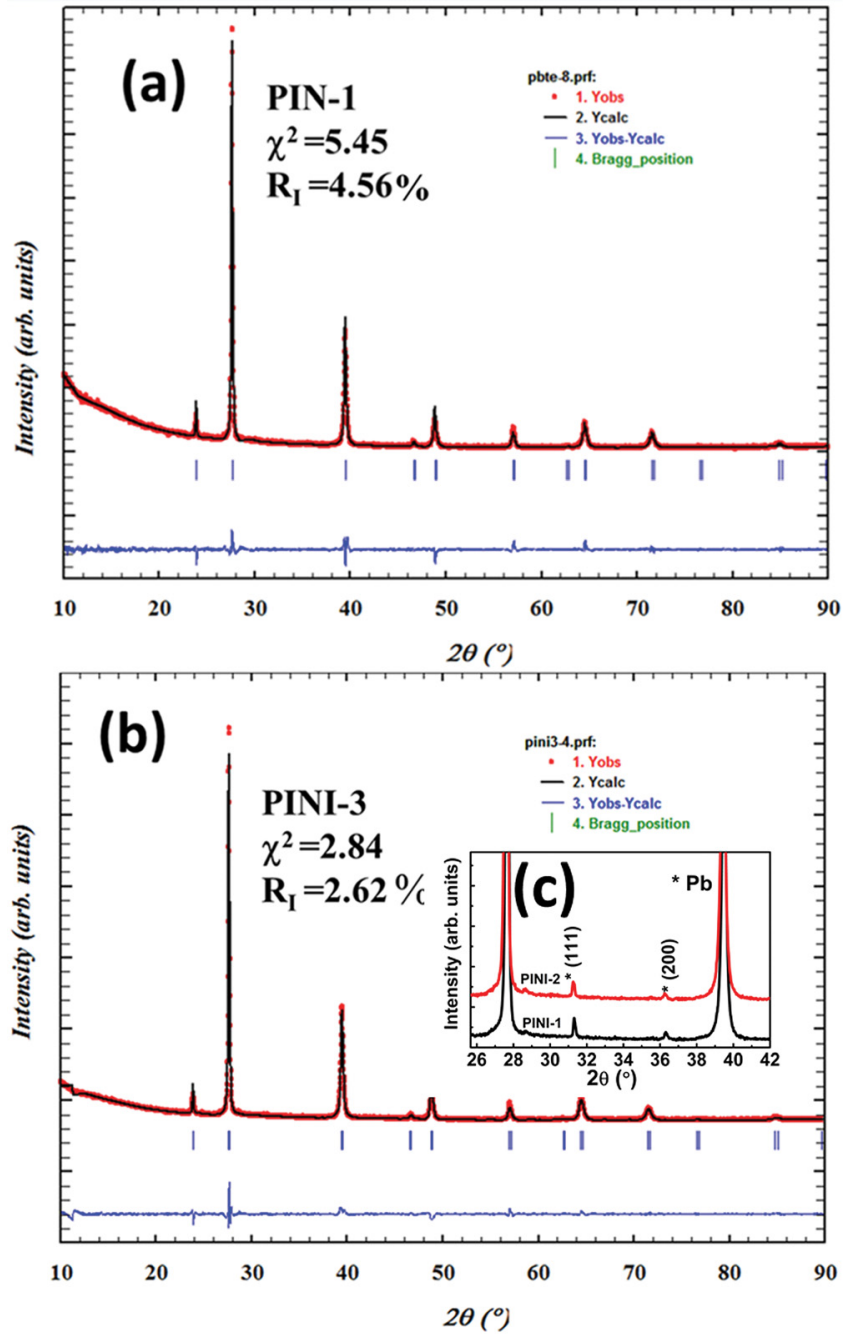

FIG. 1. Rietveld refined powder XRD for samples (a) PIN-1 and (b) PINI-3, respectively. The inset (c) shows the Pb peaks observed in PINI-1 and PINI2 samples.

with $207 \mathrm{pm}$ is almost the same as that of the I radius. Lattice parameters of the PINI series did not follow any systematic trend which may be due to the complexity of co-doping of In and I in $\mathrm{PbTe}$ and with excess of $\mathrm{Pb}$.

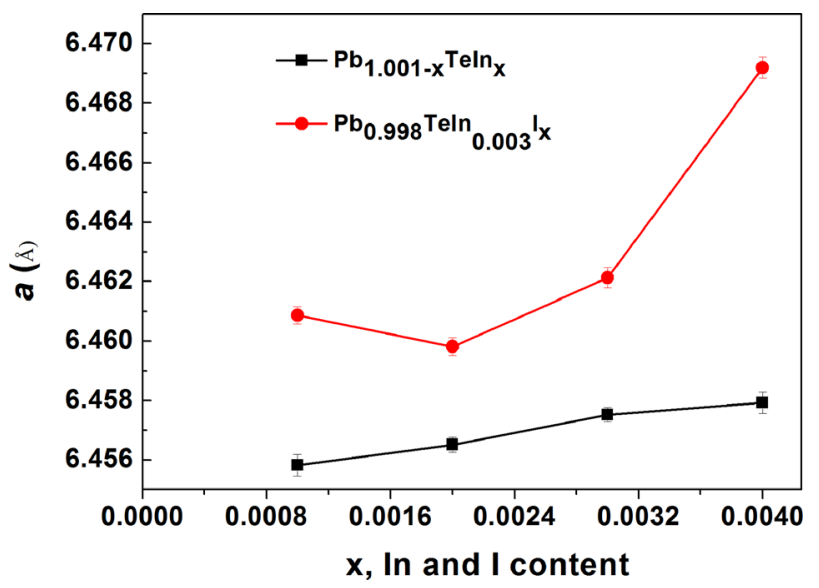

FIG. 2. Lattice parameters as a function of nominal composition for PIN and PINI samples, respectively. 


\section{B. Microstructure}

Figure 3 shows the scanning electron micrographs of representative samples PIN-1 and PINI-1 from both series. Figure 3(a) presents the polished surface of the sample PINI1. EPMA results defined that the main phase is PbTe, while small amounts of micrometer sized $\mathrm{Pb}$ phases (white color) were also detected in this compound in agreement with the results of X-ray diffraction (XRD). The WDS results (Table I) showed that $\mathrm{Pb}$ and $\mathrm{Te}$ were present in the stoichiometric ratio, while In was either present in low concentration or not detected. No iodine was detected in the EPMA, which could be because the content was only of the order 0.1 to 0.4 at. \%, much below the detectability limit. For all other samples of this series (PINI-2, PINI-3, and PINI-4), no secondary phase was found. The synthesis of the samples was repeated several times. It is worth mentioning that all these PINI-1 samples were single phase. Thus, with a careful control of the stoichiometry, $\mathrm{Pb}$ precipitation can be avoided. Figure 3(b) shows the SEM image of the fracture surface of the PINI-1 sample. Absence of pores indicates that the compaction of the material had taken place well and in proximity to the theoretical density. The average particle size was in the micrometer range. Figure 3(c) reveals the polished surface of the sample PIN-1. Single phase was observed here in agreement with the XRD result. The fracture surface of PIN-1 is shown in Figure 3(d) where the compaction of this sample is visible. This microstructure is similar to that of the PINI sample and no obvious change in microstructure was observed with the addition of iodine. Also, with increase of the dopant concentration (In and I) in both series, neither the microstructure nor particle size showed any change, indicating that indium and/or iodine did not influence the grain growth. In order to investigate further (i) whether the $\mathrm{Pb}$ precipitates occurred in nanometer scale, (ii) whether any other element like Te, In had precipitated out (iii) whether iodine was present in the samples, and also (iv) to determine the grain sizes, HRTEM was carried out on four samples doped with In ( $\mathrm{x}=0.003$ and 0.004 for PIN series) and I ( $\mathrm{y}=0.003$ and 0.004 for PINI series). These particular compositions in the PIN and PINI series were chosen because
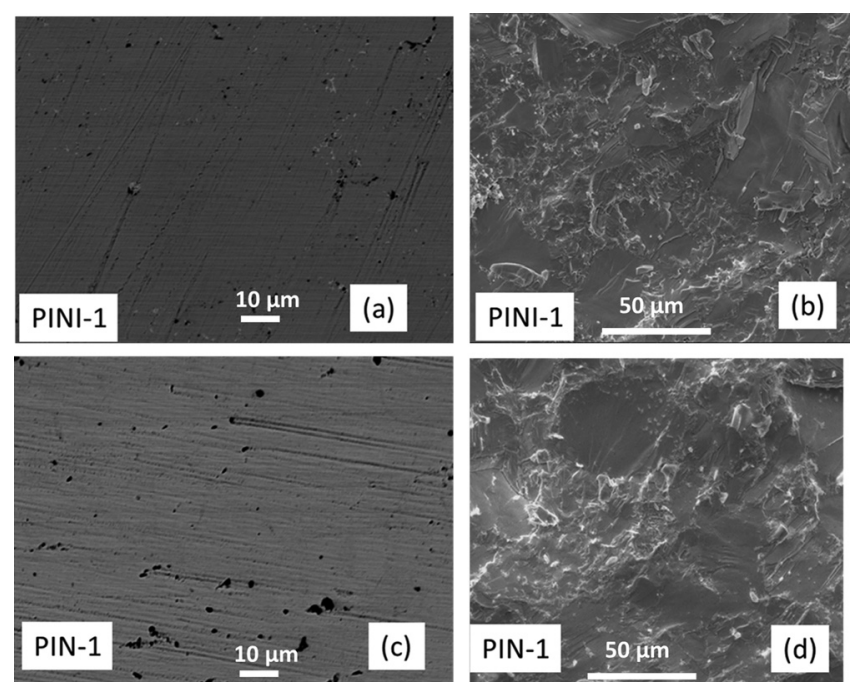

FIG. 3. BSE and SE electron images for PIN and PINI samples. it would be easier to detect indium or iodine in these samples with a higher In and I content. Figure 4(a) shows the TEM image of the PIN-3 sample representing polycrystalline features with well-defined cube structures and sharp edges and with grain sizes ranging from $10 \mathrm{~nm}$ to $80 \mathrm{~nm}$.

High magnification image (Fig. 4(b)) of this sample clearly envisages that all the grains are densely packed but differently oriented and with sharp grain boundaries. An obvious feature of the strain domain at a regular interval, as marked by arrows in Fig. 4(b), can also be seen which might result from the In doping. HRTEM image (Fig. 4(c)) from one of the particles confirms well the crystallinity of the phase. Interplanar spacing of lattice fringes corresponds to the (200) plane of the PbTe structure (space group $F m \overline{3} m$ ). The Fast Fourier Transform pattern generated from HRTEM shown in the inset (Fig. 4(c)) also confirms the PbTe particle aligned along [001], parallel to the beam direction. In order to further test the single phase condition, STEM imaging (Fig. 4(d)) has been performed confirming a uniform distribution of particles with mostly square shape and sharp edges. Thus, no evidence of precipitation of any other element like $\mathrm{Pb}$, In or I has been observed in the present sample. A similar type of microstructural feature was observed for the PIN-4 samples which are presented in Figs. 4(e)-4(h) with the difference that a little grain size variation can be noted. The grain sizes in PIN-4 are $\sim 10 \mathrm{~nm}$ to $50 \mathrm{~nm}$, smaller than those of the PIN-3 sample. In a very local region, an interesting feature of coherently embedded nano-dots as marked by a circle in Fig. 4(f) can be clearly seen. However, we were unable to deduce the composition of such a tiny nano-dot. Fig. 4(h) shows the Scanning Transmission Electron Microscopy (STEM) image of the PIN-4 sample with welldefined crystalline particles without any secondary phase. Figure 5 summarizes the TEM investigation on samples PINI-3 and PINI-4. Fig. 5(a) displays bright field electron micrograph from sample PINI-3 showing well-defined crystalline shapes. HRTEM image recorded from one particle (Fig. 5(b)) documents a well-defined cubic crystalline phase of PbTe with $\{200\}$ set of planes. The corresponding STEM image also confirms a uniform distribution of particles mostly square shaped and sharp edges in this sample too. Fig. 5(d) presents a bright field electron micrograph from sample of PINI-4 with grain sizes ranging from $<10 \mathrm{~nm}$ to $50 \mathrm{~nm}$. The lattice resolution image (Fig. 5(e)) and corresponding FFT also confirms the PbTe phase with a $\{200\}$ set of planes with spacing of $0.339 \mathrm{~nm}$. The contrast observed in bright field images (Figs. 4(a) and 4(e)) and (Figs. 5(a) and $5(\mathrm{e}))$ is the diffraction contrast where black particles are in the perfect zone axis and gray particles are away from the zone axis. The contrast observed in STEM images (both Figs. 4(d) and 5(c)) could be because of the difference in thickness since the STEM EDS point scan showed only PbTe phase irrespective of contrast in the image. The selected area electron diffraction (SAED) pattern collected from sample PIN-4 and PINI-4 is shown in Figs. 6(a) and 6(b). The characteristic ring pattern of polycrystalline materials has been observed in all the samples, irrespective of their composition. The ring patterns were indexed with a face centred cubic lattice with lattice parameter $a=6.38 \AA$. 
TABLE I. The EPMA composition and carrier concentration of the samples at room temperature.

\begin{tabular}{lccc}
\hline \hline S. No. & Sample name & Nominal composition & EPMA composition \\
\hline 1 & $\mathrm{PIN}-1$ & $\mathrm{~Pb}_{1.000} \mathrm{Te}_{1.000} \mathrm{In}_{0.001}$ & $\mathrm{~Pb}_{1.080} \mathrm{Te}_{0.990} \mathrm{In}_{0.000}$ \\
2 & $\mathrm{PIN}-2$ & $\mathrm{~Pb}_{0.999} \mathrm{Te}_{1.000} \mathrm{In}_{0.002}$ & 3.566 \\
3 & $\mathrm{PIN}-3$ & $\mathrm{~Pb}_{0.998} \mathrm{Te}_{1.000} \mathrm{In}_{0.003}$ & 3.757 \\
4 & $\mathrm{PIN}-4$ & $\mathrm{~Pb}_{0.997} \mathrm{Te}_{1.000} \mathrm{In}_{0.004} \mathrm{Te}_{1.001} \mathrm{In}_{0.002}$ & 3.492 \\
5 & $\mathrm{PINI}-1$ & $\mathrm{~Pb}_{0.998} \mathrm{In}_{0.003} \mathrm{Te}_{1.000} \mathrm{I}_{0.001}$ & $\mathrm{Te}_{0.983} \mathrm{In}_{0.001}$ \\
6 & $\mathrm{PINI}-2$ & $\mathrm{~Pb}_{0.998} \mathrm{In}_{0.003} \mathrm{Te}_{1.000} \mathrm{I}_{0.002}$ & $\mathrm{~Pb}_{1.087} \mathrm{Te}_{0.987} \mathrm{In}_{0.001} \mathrm{Te}_{0.989} \mathrm{I}_{0.000}$ \\
7 & $\mathrm{PINI}-3$ & $\mathrm{~Pb}_{0.998} \mathrm{In}_{0.003} \mathrm{Te}_{1.000} \mathrm{I}_{0.003}$ & $\mathrm{~Pb}_{1.106} \mathrm{In}_{0.000} \mathrm{Te}_{1.000} \mathrm{I}_{0.000}$ \\
8 & $\mathrm{PINI}-4$ & $\mathrm{~Pb}_{1.092} \mathrm{In}_{0.002} \mathrm{Te}_{0.983} \mathrm{I}_{0.000}$ & 2.973 \\
\hline \hline
\end{tabular}
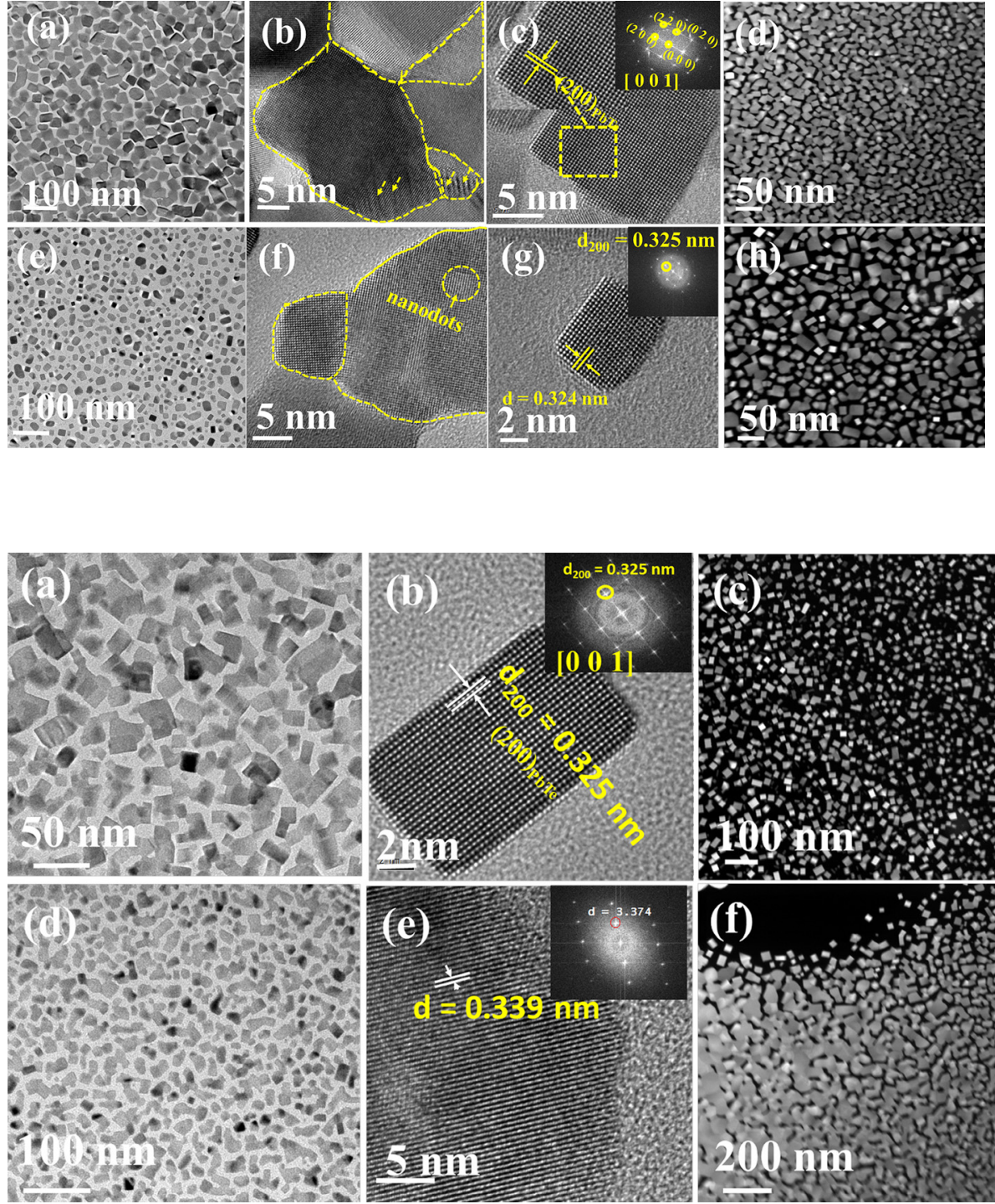

Fig. 6(c) displays high resolution image of two grains from sample PIN-4 separated by a well-defined boundary. The higher magnification image from region within the selected rectangle in Fig 6(c) shows atomic columns of two grains separated by a low angle grain boundary. A clear arrangement of dislocation along the grain boundary is visible inbetween the two grains. A similar arrangement of dislocations has been observed in other samples also with different compositions.

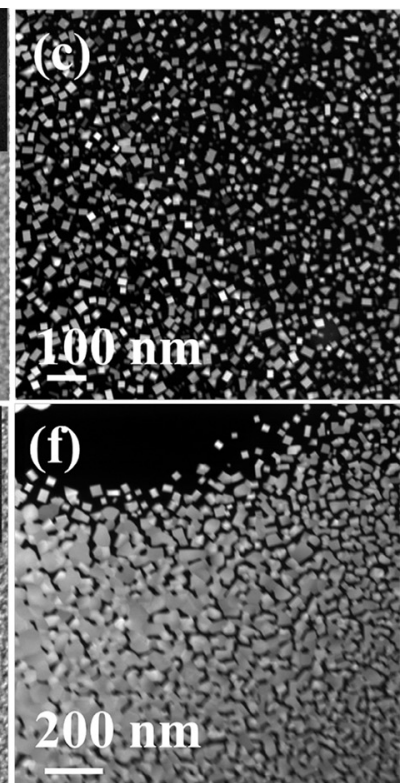

FIG. 5. (a)-(c) TEM micrographs corresponding to PINI-3 sample showing a single phase contrast (b) HRTEM image confirming the crystalline particles to be of PbTe phase. (c) STEM image of PINI-3 sample showing clarity of crystals with single phase contrast. Figs. 5(d)-(f) corresponds TEM and STEM images obtained from sample of PINI-4 in similar fashion revealing the single phase $\mathrm{PbTe}$ cubic structure.

\section{TRANSPORT PROPERTIES}

\section{A. Seebeck coefficient}

Figure 7 displays the Seebeck coefficient of all the PIN and PINI samples in the temperature range from $300 \mathrm{~K}$ to $800 \mathrm{~K}$. All the samples are n-type, indicating that electrons are the majority of the carriers throughout the measured temperature range. The values at room temperature are in the range of -60 to $-70 \mu \mathrm{V} / \mathrm{K}$ except for the sample PIN-4 for 


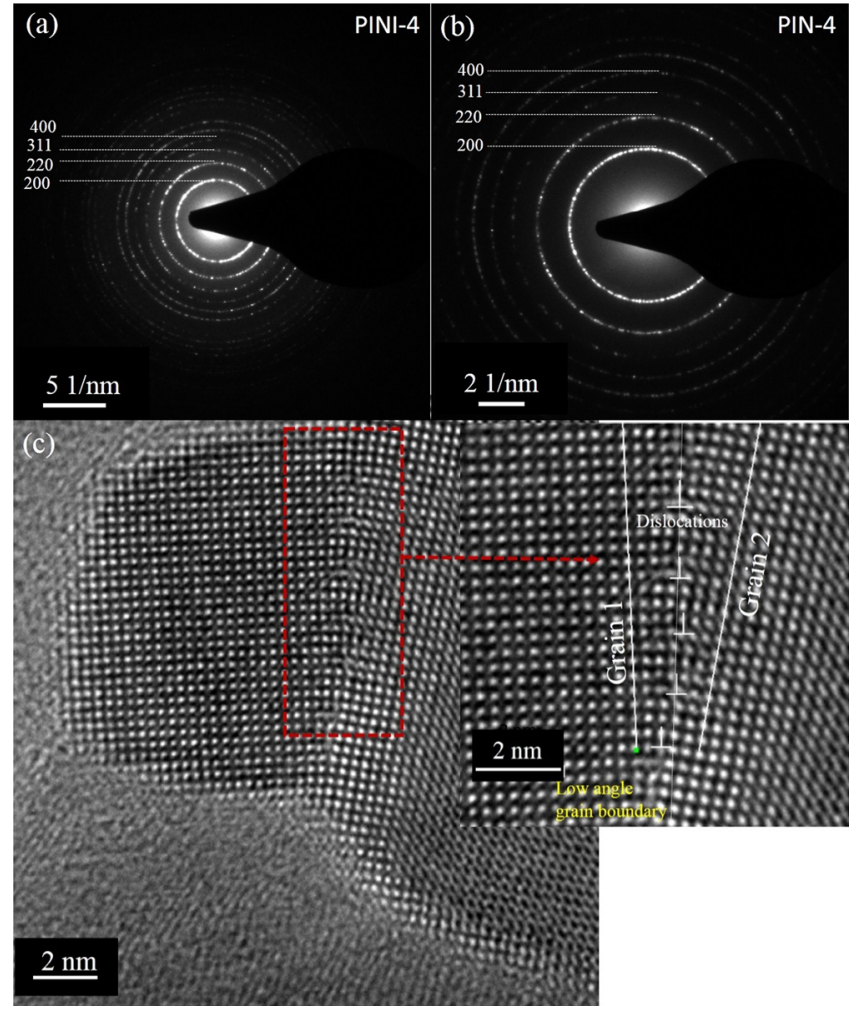

FIG. 6. Selected area electron diffraction (SAED) pattern of (a) PIN-4 and (b) PINI-4 (c) grain boundary of PIN-4 sample along with the higher magnification image from selected rectangle.

which the absolute value at room temperature is slightly higher, namely $-90 \mu \mathrm{V} / \mathrm{K}$. This can be correlated to the carrier concentration $(n)$ (Table I), measured at room temperature. The values of $n$ for PIN-1, PIN-2, and PIN-3 are almost the same, while for PIN-4, $n=2.4 \times 10^{19} \mathrm{~cm}^{-3}$ is lower resulting in a higher Seebeck coefficient. The observed carrier concentration values were almost one order of magnitude higher than the values reported for the In doped samples. ${ }^{19}$ This large difference of the $n$ values in comparison to the other reports may be due to the excess of added $\mathrm{Pb}$ in the present work. A carrier concentration almost invariant with doping could stem from the addition of In, which plays

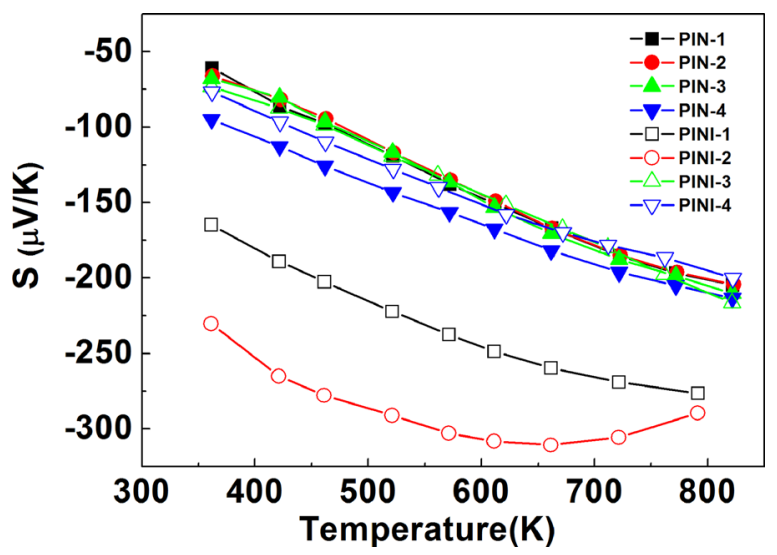

FIG. 7. Temperature dependent Seebeck coefficient of all the PIN and PINI samples. the role of controlling the carrier concentration, and thus, the optimisation of the thermal and electronic transport. A slightly lower charge carrier density value for PIN-4, compared to the other samples, may occur from the presence of non-stoichiometry and/or native point defects, introduced during the sample synthesis. The values of $S$ for the PIN samples almost linearly increase with temperature and reach up to $-220 \mu \mathrm{V} / \mathrm{K}$ at $800 \mathrm{~K}$. This is in contrast to the values obtained by Guch et al., ${ }^{19}$ who reported for indium doped samples room temperature values in the range from -150 to $-200 \mu \mathrm{V} / \mathrm{K}$ and slightly higher values, up to $-250 \mu \mathrm{V} / \mathrm{K}$ at $650 \mathrm{~K}$, receiving almost stable values over the whole measurement range.

The stability of the Seebeck values over a large temperature range is possibly linked to the Fermi level pinning by In $^{3+}$ ions. ${ }^{17}$ The reason why pinning is not observed in our samples could possibly be due to the lower In content as compared to Guch et al. ${ }^{19}$ and the excess of $\mathrm{Pb}$. The electrons supplied by the excess $\mathrm{Pb}$ could compensate the pinning effect. The Seebeck coefficient (S) of the PINI samples displays a variation with the iodine content: $\mathrm{S}$ decreases with increasing iodine content. The Seebeck coefficients of all samples are negative, indicating that the majority of the carriers are electrons. The sample with the highest iodine content (PINI-4) revealed Seebeck values similar to PINI-3. Room temperature values of $\sim-200 \mu \mathrm{V} / \mathrm{K}$ were obtained for PINI-1, while for PINI-2, PINI-3, and PINI-4 the absolute values decreased $(\sim-125 \mu \mathrm{V} / \mathrm{K}$ and $-75 \mu \mathrm{V} / \mathrm{K}$, respectively). This behavior indicates the systematic variation of the carrier concentration by iodine in PbTe for the samples PINI-1, 2, and 3. The Seebeck coefficient of PINI-4 did not decrease with further iodine doping; this may be due to the cancellation effect of the carrier concentration influenced by indium, restricting a further increase of the carrier concentration by iodine. PINI-2 showed a maximum at $650 \mathrm{~K}$ after which the values decreased again, probably due to occurrence of thermally generated carriers at higher temperature. It can be seen in Figure 10 that the room temperature mobility was higher for PINI-2 than PINI-1. Second, for PINI-1 and PINI-2 samples, the observed composition from EPMA shows that no indium was detected in PINI-2 while PINI-1 showed some amount of In. This means that PINI-2 is more or less like an undoped but non-stoichiometric PbTe. It is possible that indium could have played some role in the suppression of a bipolar effect which could not be done in PINI2 sample. The fact that non-stoichiometric PbTe can show bipolar effect at $\mathrm{T}>700 \mathrm{~K}$ can be further supported by $\mathrm{Su}$ et $a l .{ }^{26}$ who measured only up to $\sim 740 \mathrm{~K}$, obtained flattening of Seebeck at $\mathrm{T}>700 \mathrm{~K}$.

It was reported by Guch et $a .^{23}$ for indium and iodine doping that with an increase of the indium content a further rise of carriers from iodine doping was restricted. Guch et $a l .{ }^{23}$ obtained Seebeck values for indium and iodine doped samples $-220 \mu \mathrm{V} / \mathrm{K}$ for $\operatorname{In}_{0.005} \mathrm{~Pb}_{0.995} \mathrm{Te}_{0.999} \mathrm{I}_{0.001}$ to $-135 \mu \mathrm{V} / \mathrm{K}$ for $\mathrm{In}_{0.005} \mathrm{~Pb}_{0.995} \mathrm{Te}_{0.994} \mathrm{I}_{0.006}$ at room temperature. The Seebeck coefficient values in the present work are lower in comparison to the reported ones. The reason for this difference could be the change in the carrier concentration values observed in this work $\left(\sim 10^{19} \mathrm{~cm}^{-3}\right)$ compared to 
reported data $\left(\sim 10^{18} \mathrm{~cm}^{-3}\right) \cdot{ }^{19,23}$ The excess of $\mathrm{Pb}$ with indium and iodine doping might have influenced this variation in the values of $n$. On the other hand, LaLonde ${ }^{20}$ has shown iodine as a good n-type dopant in PbTe with carrier concentrations $\sim 10^{19} \mathrm{~cm}^{-3}$, similar to the values obtained in the present study. Second, the values for PINI-1 throughout the temperature range are higher than those obtained by LaLonde et al. which could possibly originate from the small grain sizes as seen in the TEM images, which may have provided a carrier filtering effect leading to slightly enhanced Seebeck coefficients.

Table I summarizes the results of the room temperature Hall measurement for all samples. All the samples showed an electron concentration in the range $\sim 10^{19} \mathrm{~cm}^{-3}$ as typical for degenerate semiconductors. LaLonde et al. ${ }^{20}$ also obtained $n$ of the same order of magnitude for a similar iodine content. The Pisarenko plot at room temperature is presented in Figure 8. Theoretical calculations were done using the Single Kane Band (SKB) model with the following equations: ${ }^{27}$

Hall carrier density

$$
n_{H}=\frac{1}{e R_{H}}=A^{-1} \frac{\left(2 m^{*} k_{B} T\right)^{3 / 2}}{3 \pi^{2} \hbar^{3}}{ }^{0} F_{0}^{3 / 2} .
$$

Hall factor

$$
A=\frac{3 K(K+2)}{(2 K+1)^{2}} \frac{{ }^{0} F_{-4}^{1 / 2} \cdot{ }^{0} F_{0}^{3 / 2}}{\left({ }^{0} F_{-2}^{1}\right)^{2}}
$$

Hall mobility

$$
\mu_{H}=A \frac{2 \pi \hbar^{4} e C_{l}}{m_{I}^{*}\left(2 m_{b}^{*} k_{B} T\right)^{3 / 2} E_{d e f}^{2}} \frac{3^{0} F_{-2}^{1}}{{ }^{0} F_{0}^{3 / 2}} .
$$

Seebeck coefficient

$$
S=\frac{k_{B}}{e}\left[\frac{{ }^{1} F_{-2}^{1}}{{ }^{0} F_{-2}^{1}}-\xi\right],
$$

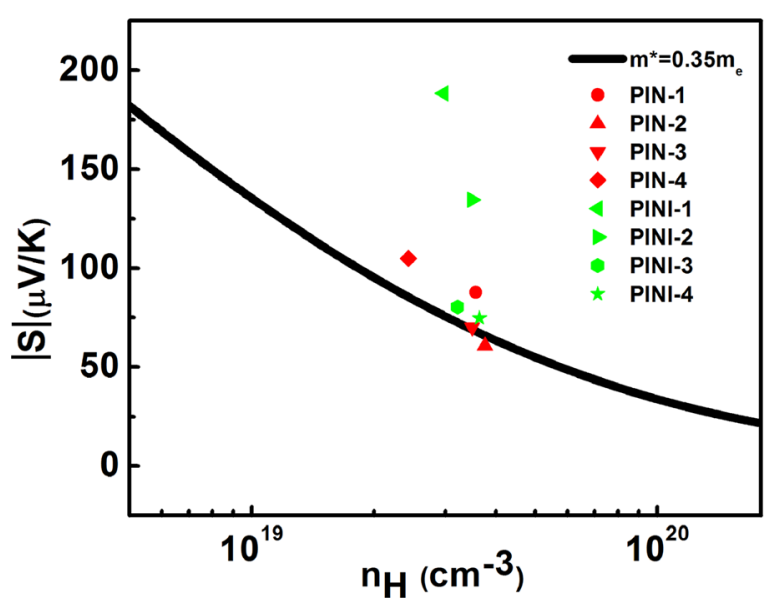

FIG. 8. Room temperature Pisarenko plot for PIN and PINI samples. where ${ }^{n} F_{k}^{m}$ has a similar form as Fermi integer

$$
{ }^{n} F_{k}^{m}=\int_{0}^{\infty}\left(-\frac{\partial f}{\partial \varepsilon}\right) \varepsilon^{n}\left(\varepsilon+\alpha \varepsilon^{2}\right)^{m}\left[(1+2 \alpha \varepsilon)^{2}+2\right]^{k / 2} d \varepsilon .
$$

Here $\mathrm{k}_{\mathrm{B}}=1.38 \times 10^{-23} \mathrm{~J} / \mathrm{K}$, e is the carrier charge, $\mathrm{m}_{\mathrm{b}} *$ is the band effective mass, $m_{I}^{*}$ is the inertial effective mass, $\hbar$ is the reduced Planck's constant, ${ }^{n} F_{k}^{m}$ are Fermi integrals, $\varepsilon$ is the carrier energy, $\mathrm{K}=m_{\|}^{*} / m_{\perp}^{*}, \alpha=\mathrm{k}_{\mathrm{B}} \mathrm{T} / \mathrm{E}_{\mathrm{g}}$ where $\mathrm{E}_{\mathrm{g}}$ is the band gap and $\mathrm{E}_{\text {def }}^{2}$ is the deformation potential of the material. The indium-doped samples (PIN series) agree with the theoretical plot, which shows the absence of any resonant doping. The scatter in the iodine-doped samples could be either due to experimental errors or reflects the variation in $n$ due to defects introduced by the synthesis, which cannot be quantified easily.

\section{B. Electrical resistivity}

Figure 9 depicts the electrical resistivity of all the samples (both PIN and PINI series) in the temperature range from $300 \mathrm{~K}$ to $800 \mathrm{~K}$. All the samples show an increase of resistivity with temperature, which indicates the degenerate nature of the samples, in agreement with the Hall results. For the PIN samples, electrical resistivity slightly increased with increasing In content, consistent with the Seebeck coefficient data. Electrical resistivity values were observed in the range between $0.4 \mathrm{~m} \Omega$-cm and $0.8 \mathrm{~m} \Omega$-cm for all the samples at room temperature. These values are lower than the $\rho$ values of $1 \mathrm{~m} \Omega-\mathrm{cm}$ reported ${ }^{19}$ for the 0.1 and 0.5 at. \% In doped samples at room temperature. The lower $\rho$-values observed in the present work are due to the higher carrier concentration in comparison to the reported values. ${ }^{19}$ Figure 10 defines the mobility variation versus carrier concentration along with theoretically calculated values. The average mobility for all the samples was $\sim 400 \mathrm{~cm}^{2} / \mathrm{V}$ s. Figure 11 shows the mobility variation for the PIN and PINI series versus nominal composition. For pure PbTe, both the curves should converge to the same point. However, this does not happen since the observed EPMA composition is different from the nominal composition, as seen in Table I. The carrier concentration

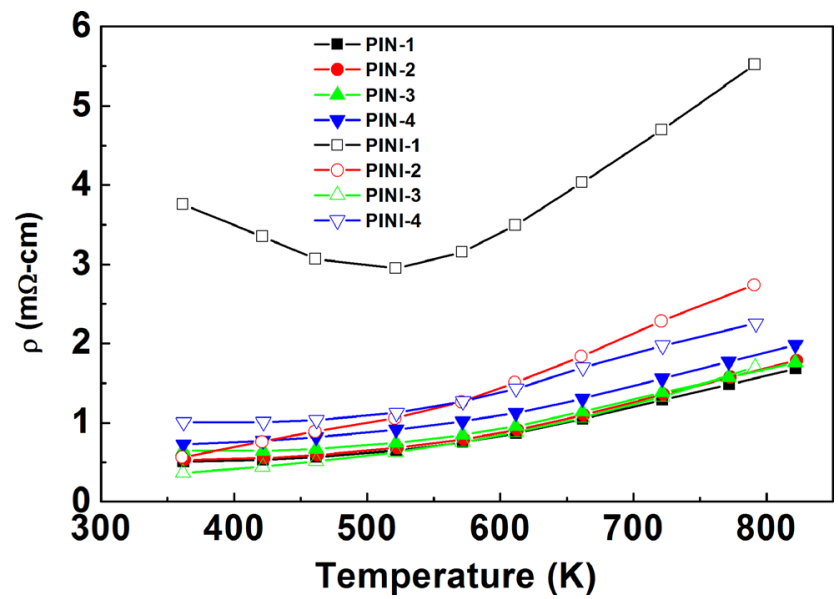

FIG. 9. Temperature dependent electrical resistivity for PIN and PINI samples. 


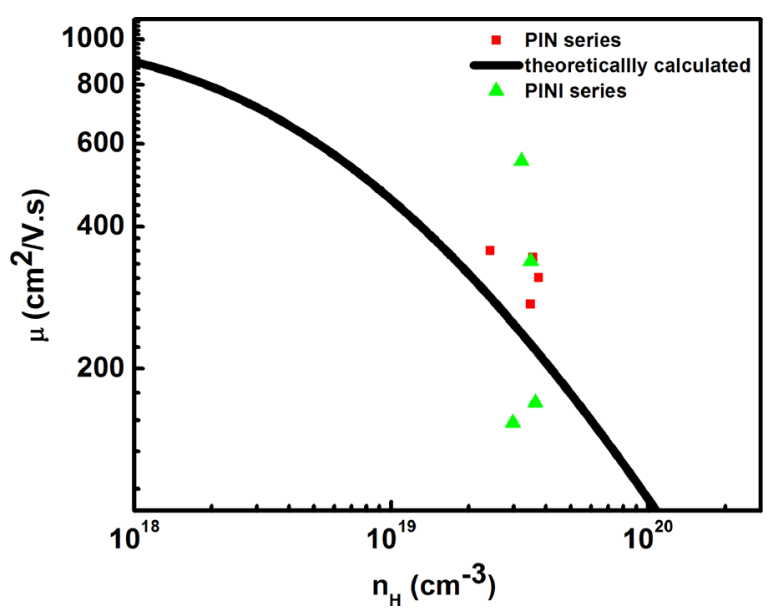

FIG. 10. Mobility variation with carrier concentration along with theoretically calculated values.

of PIN-1, 2, 3 is almost constant (Table I), whereas a slight decrease of mobility with In doping occurs for PIN-1 to PIN-3 (Figure 11). Therefore, it is clear that an increase of the electrical resistivity with increase of dopant could be due to the slight reduction of the carrier mobility caused by point defect scattering and ionised impurity scattering.

In contrast to the PIN series, the electrical resistivity values of In and I doped samples (PINI) decreased with increase of the dopant content except for the highest dopant content. It was already reported ${ }^{20}$ that only I-doped PbTe showed a decrease of $\rho$ due to the increase of carrier concentration caused by substitution of I (creates one extra electron) for Te. Also in another report, ${ }^{23}$ in which simultaneous doping of In and I was studied, it was shown that the electrical resistivity decreased with I doping due to the creation of additional electrons by substitution of I on the Te site. In the present work, it is believed that the effect of iodine doping on electrical resistivity of In doped samples was prominent.

The electrical resistivity varied between values 0.4-1.4 m $\Omega$-cm for all the samples at room temperature. These values are lower in comparison to the resistivity values reported ${ }^{23}$ for the In and I doped samples and are comparable to $\mathrm{PbI}_{2}$ doping ${ }^{17}$ for different mol. \% of $\mathrm{PbI}_{2}$.

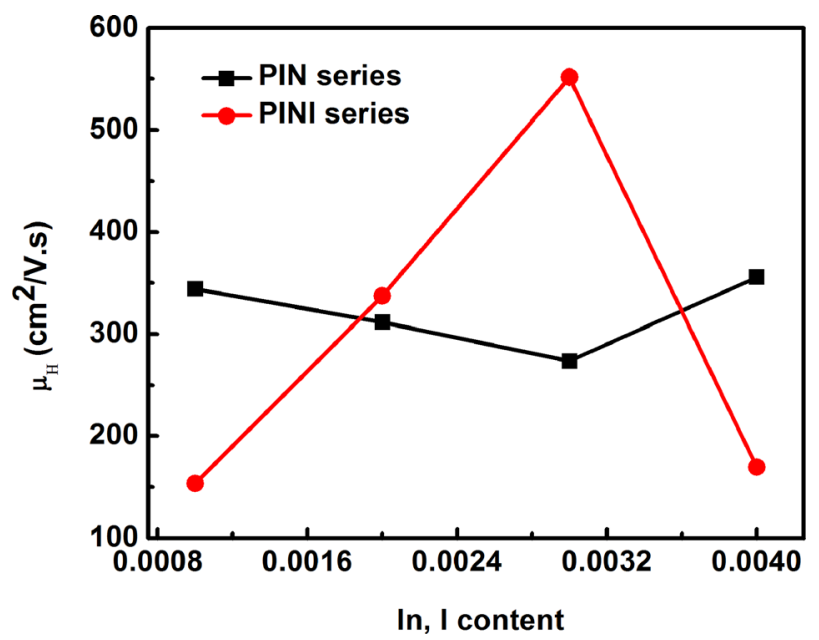

FIG. 11. Mobility variation with nominal composition for PIN and PINI series.
Therefore, in the present work, low doping levels of indium with slight excess of $\mathrm{Pb}$ leads to the optimisation of carrier concentration $\left(10^{19} \mathrm{~cm}^{-3}\right)$. Summarizing, there is not much variation of mobility when only the In content changes in the PIN samples, while for the PINI samples, a variation is seen, which indicates the role of iodine in the carrier concentration. Since the microstructure proved a similar grain size distribution for both PIN as well as PINI samples, its influence on the mobility can be neglected here. The resistivity values of the PIN samples increase systematically with increase of In content while the PINI samples show a slight decrease with increase of iodine content. This could be due to an almost constant mobility for the PIN series whilst an increase of the carrier concentration is inferred by I doping in the PINI samples. Iodine belongs to group VII, substitutes for Te and donates one electron to the system.

\section{Power factor}

The power factor $\left(\mathrm{S}^{2} / \rho\right)$ versus temperature for both series of samples is plotted in Figure 12. For the PIN samples the values are high $\sim 25 \mu \mathrm{W} / \mathrm{cm}-\mathrm{K}^{2}$ at $700 \mathrm{~K}$ and above, while the highest power factor obtained for the PINI series varied between $16 \mu \mathrm{W} / \mathrm{cm}-\mathrm{K}^{2}$ and $28 \mu \mathrm{W} / \mathrm{cm}-\mathrm{K}^{2}$. The power factor - temperature-curves for the PIN samples, PINI-3 and PINI-4 are flattening out at $700 \mathrm{~K}$ and above, probably due to the optimisation of the carrier concentration. PINI-2, on the other hand, shows high room temperature values $\sim 35 \mu \mathrm{W}$ / $\mathrm{cm}-\mathrm{K}^{2}$, due to high Seebeck coefficients.

\section{Thermal conductivity}

In Figure 13, we plot the total thermal conductivity $\left(\kappa_{\text {total }}\right)$ of all the samples (both PIN and PINI series) from $300 \mathrm{~K}$ to $800 \mathrm{~K}$. Total thermal conductivity was almost the same for all the In doped samples except for PIN-3, which showed a lower thermal conductivity. The total thermal conductivity decreased with increase of temperature for the samples PIN-1, 2, 4 whereas an increase of $\kappa_{\text {total }}$ was observed for PIN-3 samples, which could be a signature of the bipolar conduction. The room temperature values of the PIN samples are higher than those of the PINI samples. The total thermal conductivity of the PINI samples increased with increase of I

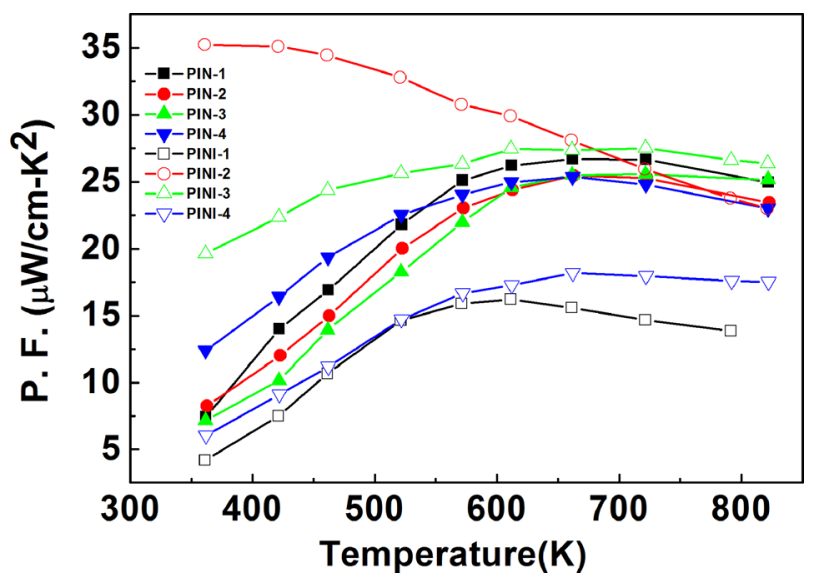

FIG. 12. Temperature dependent power factor for PIN and PINI samples. 


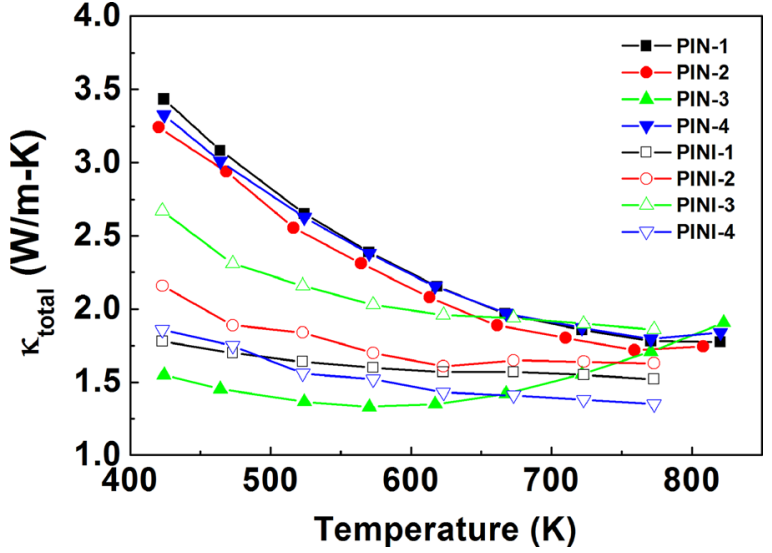

FIG. 13. Temperature dependent total thermal conductivity for PIN and PINI samples.

doping, whereas it was decreased for the sample PINI-4. The $\kappa_{\text {total }}$ decreased with increase of temperature for all the PINI samples and showed a minimum value of $\sim 1.3 \mathrm{~W} / \mathrm{m}-\mathrm{K}$ at $773 \mathrm{~K}$ for PINI-4. The $\kappa_{\text {total }}$ values of the PINI samples are slightly higher than those reported by $\mathrm{Guch}^{23}$ for the In and I doped samples but are lower than those reported by Orihashi et $a l .^{28}$ This variation could possibly be due to the difference in the carrier part of the thermal conductivity. For both series, there was no systematic trend observed with the increase of doping, which may be due to the influence of carrier concentration (which means carrier thermal conductivity) and lattice thermal conductivity (can be related by the point defects, mass fluctuation scattering induced by doping). A similar type of results of thermal conductivity (i.e. no systematic trend with doping) was reported ${ }^{23}$ for In and I doped PbTe samples. The lattice contribution to the total thermal conductivity $\left(\kappa_{1}\right)$ was found out by the relation $\kappa_{\text {total }}=\kappa_{1+} \kappa_{\mathrm{e}}$, where $\kappa_{\mathrm{l}}$ is the lattice contribution and $\kappa_{\mathrm{e}}$ is the electronic contribution calculated from the Wiedemann Franz relation $\kappa_{\mathrm{e}}=\mathrm{LT} / \rho$, where $\mathrm{L}$ is the Lorenz number. The Lorenz number was calculated using the following formula:

$$
L=\left(\frac{k}{e}\right)^{2} \frac{(1+r)(3+r) F_{r}(\eta) F_{r+2}(\eta)-(2+r)^{2} F_{r+2}(\eta)^{2}}{(1+r)^{2} F_{r+2}(\eta)^{2}}
$$

where $r$ is the scattering factor. Here, temperature dependent Lorenz number values varied from $1.4 \times 10^{-8} \mathrm{~W} \Omega \mathrm{K}^{-2}$ to $2.0 \times 10^{-8} \mathrm{~W} \Omega \mathrm{K}^{-2}$ over the entire temperature range for the samples. The lattice thermal conductivity $\kappa_{1}$ as a function of temperature is displayed in Figure 14 for all PIN and PINI samples. For all the PIN samples, except for PIN-3, $\kappa_{1}$ decreases with increasing temperature, indicating scattering by acoustic phonons. It has been shown ${ }^{29}$ that alloying is effective for reducing $\kappa_{1}$ up to $45 \%$ as compared to the undoped parent $\mathrm{PbTe}$. Moreover, using other strategies ${ }^{30}$ like multilayering, it is possible to reduce the thermal conductivity below that of the parent compound as well as lower than the amorphous limit. In the present study, the lower $\kappa_{1}$ of the PIN-3 sample might possibly be due to doping of this compound so that the disorder here is a maximum leading to the lowest $\kappa_{1}$. These values become constant at temperatures

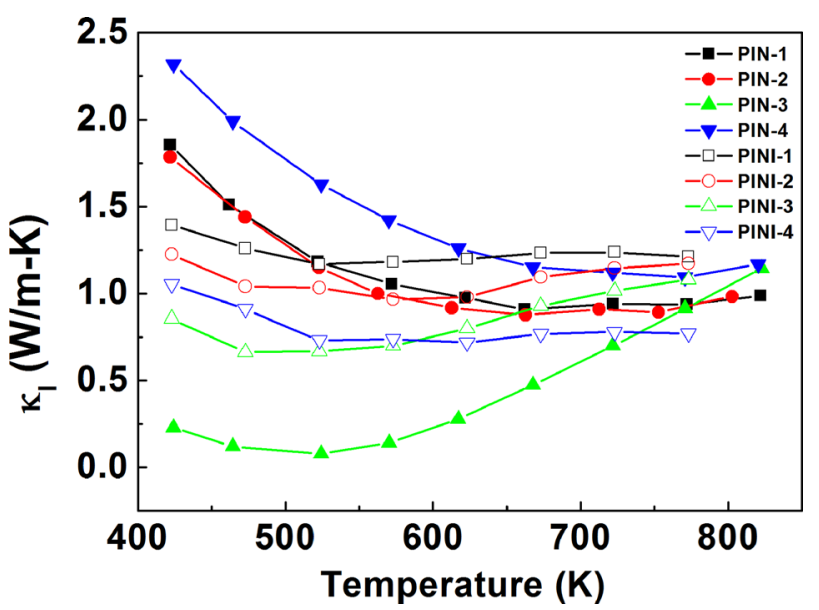

FIG. 14. Temperature dependent lattice thermal conductvity for PIN and PINI samples.

$>700 \mathrm{~K}$, which infer the onset of bipolar conduction. For PIN-3, the onset occurs at $500 \mathrm{~K}$. The PINI samples generally exhibit lower values of $\kappa_{1}$ probably due to doping at both the $\mathrm{Pb}$ and $\mathrm{Te}$ site, which lead to a higher disorder as compared to the PIN series and hence, a lower thermal conductivity. For these samples too, bipolar conduction onset occurred at temperatures $\sim 500 \mathrm{~K}$. The lattice thermal conductivity values were comparable to the values reported for In and I doped samples. ${ }^{28}$ This confirms the effect of double doping (In and I) on lattice thermal conductivity, i.e., point defects significantly increased scattering of the heat carrying phonons.

\section{E. Figure of merit (zT)}

The thermoelectric figure of merit $(z \mathrm{~T})$ versus temperature is presented in Figure 15 for both series of samples. The highest $z \mathrm{~T}$ was obtained at $675 \mathrm{~K}$ for the PIN-3 sample, while for PIN-2 and PIN-3, zT $\sim 1$ was achieved. The values for the PIN series, where only In was doped are higher than those reported by Guch et al. ${ }^{19}$ who obtained $z \mathrm{~T}=0.45$ at $650 \mathrm{~K}$. The increase in our values is due to a proper control of the carrier concentration by excess $\mathrm{Pb}$ and simultaneous

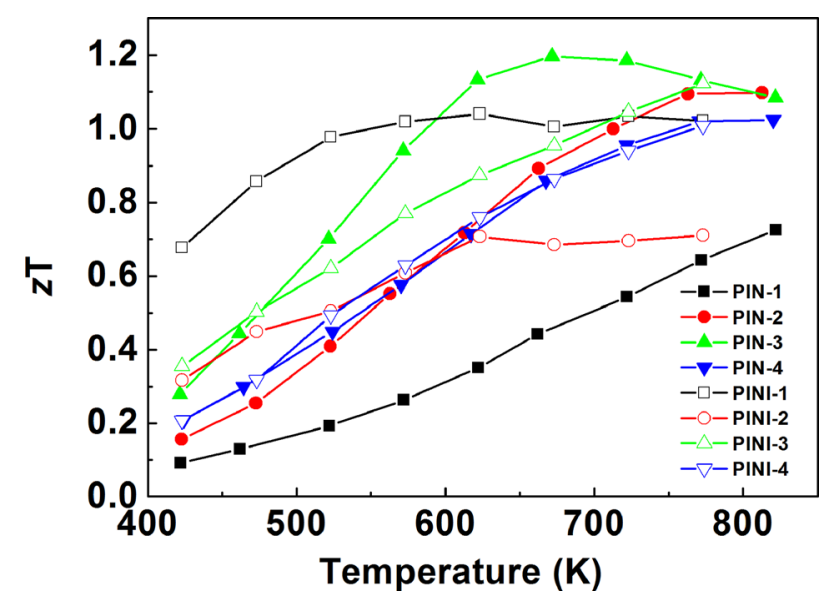

FIG. 15. Temperature dependent thermoelectric figure of merit (zT) for PIN and PINI samples. 
doping of In which scattered phonons. For the PINI series, the highest $z \mathrm{~T}$ obtained was 1.1 at $775 \mathrm{~K}$ for PINI-3. This $z \mathrm{~T}$ value is also higher than the value reported for In and I doped samples, which could possibly be caused by the optimization of carrier concentration with low level doping of indium and iodine in the present work.

\section{CONCLUSIONS}

Thermoelectric properties of In doped PbTe as well as In and I co-doped PbTe were studied with the help of microstructural and phase characterization. XRD and SEM revealed that all the prepared samples of the PIN and PINI series were single phase, whereas the PINI-1, 2 samples showed a trace of $\mathrm{Pb}$ as an impurity phase. Electrical resistivity and Seebeck coefficient were explained with the help of carrier concentration data obtained by Hall measurements. Both series, PIN and PINI, confirmed degenerate semiconducting behaviour. Both sample series showed negative Seebeck coefficients in the entire measurement range indicating that the majority of the carriers were electrons. Optimisation of the Seebeck coefficient and resistivity was obtained by the addition of excess $\mathrm{Pb}$ and doping with In for the samples of the PIN series. For the PINI samples, optimisation was achieved by doping with I and a fixed low doping level of indium. Both series showed a decrease of the thermal conductivity with increase of temperature, indicating the dominance of phonon scattering at higher temperatures. Indium doping with excess of $\mathrm{Pb}$ for the PIN samples and co-doping of In and I for the PINI samples lead to the low values of thermal conductivity, possibly influenced by point defect scattering. The combined effect of optimised carrier concentration control with low thermal conductivity values caused the enhancement of the thermoelectric figure of merit for both series of samples as compared to the reported data. Maximum $z \mathrm{~T}$ values were reached above 1 for both series of samples studied.

\section{ACKNOWLEDGMENTS}

The authors would like to acknowledge Department of Science and Technology (DST), India, for their financial support through Grant No. SB/EMEQ-243/2013 and Mr. Sayan Das, graduate student, IISc Bangalore, India, for helping us in Hall measurement.
${ }^{1}$ Y. Pei, A. D. LaLonde, N. A. Heinz, X. Shi, S. Iwanaga, H. Wang, L. Chen, and G. J. Snyder, Adv. Mater. 23, 5674 (2011).

${ }^{2}$ Y. Pei, H. Wang, and G. J. Snyder, Adv. Mater. 24, 6125 (2012).

${ }^{3}$ J. P. Heremans, V. Jovovic, E. S. Toberer, A. Saramat, K. Kurosaki, A. Charoenphakdee, S. Yamanaka, and G. J. Snyder, Science 321, 554 (2008).

${ }^{4}$ G. D. Mahan and J. O. Sofo, Proc. Natl. Acad. Sci. 93, 7436 (1996).

${ }^{5}$ S. Roychowdhury, U. S. Shenoy, U. V. Waghmare, and K. Biswas, Angew. Chem. Int. Ed. 54, 15241 (2015).

${ }^{6}$ S. Roychowdhury, S. Shenoy, U. V. Waghmare, and K. Biswas, Appl. Phys. Lett. 108, 193901 (2016).

${ }^{7}$ K. Biswas, J. J. He, Q. Zhang, G. Wang, C. Uher, V. P. Dravid, and M. G. Kanatzidis, Nat. Chem. 3, 160 (2011).

${ }^{8}$ K. Biswas, J. He, I. D. Blum, C. Wu, T. P. Hogan, D. N. Seidman, V. P. Dravid, and M. G. Kanatzidis, Nature 489, 414 (2012).

${ }^{9}$ J. Androloukias, R. P. K. F. Hsu, H. Kong, C. Uher, J. J. D'Angelo, A. Downey, T. Hogan, and M. G. Kanatzidis, Adv. Mater. 18, 1170 (2006).

${ }^{10}$ B. Poudel, Q. H. Ma, Y. Lan, A. Minnich, B. Yu, X. Yan, D. Wang, A. Muto, D. Vashaee, X. Chen, J. Liu, M. S. Dresselhaus, G. Chen, and Z. Ren, Science 320, 634 (2008).

${ }^{11}$ W. Liu, X. Tan, K. Yin, H. Liu, X. Tang, J. Shi, Q. Zhang, and C. Uher, Phys. Rev. Lett. 108, 166601 (2012).

${ }^{12}$ Y. Pei, X. Shi, A. D. LaLonde, H. Wang, L. Chen, and G. J. Snyder, Nature 473, 66 (2011).

${ }^{13}$ C. Jeong, R. Kim, and M. S. Lundstrom, J. Appl. Phys. 111, 113707 (2012).

${ }^{14}$ H. J. Goldsmid, J. Electron. Mater. 42, 1482 (2013).

${ }^{15}$ S. Ahmad, K. Hoang, and S. D. Mahanti, Phys. Rev. Lett. 96, 056403 (2006).

${ }^{16}$ S. D. Mahanti, K. Hoang, and S. Ahmad, Physica B 401-402, 291 (2007).

${ }^{17}$ Y. Gelbstein, Z. Dashevsky, and M. P. Dariel, Physica B 363, 196 (2005).

${ }^{18}$ E. P. Skipetrov, E. A. Zvereva, O. S. Volkova, E. I. Slyn'ko, and A. M. Mousalitin, Mater. Sci. Eng. B91-92, 416 (2002).

${ }^{19}$ M. Guch, C. R. Sankar, J. Salvador, G. Meisner, and H. Kleinke, Sci. Adv. Mater. 3, 615 (2011).

${ }^{20}$ A. D. LaLonde, Y. Pei, and G. J. Snyder, Energy Environ. Sci. 4, 2090 (2011).

${ }^{21}$ A. Bali, H. Wang, G. J. Snyder, and R. C. Mallik, J. Appl. Phys. 116, 033707 (2014).

${ }^{22}$ A. Bali, I.-H. Kim, P. Rogl, and R. C. Mallik, J. Electron. Mater. 43, 1630 (2014).

${ }^{23}$ M. Guch, C. R. Sankar, J. R. Salvador, G. P. Meisner, and H. Kleinke, J. Appl. Phys. 111, 063706 (2012).

${ }^{24}$ C. Long, X. Hou, Y. Gelbstein, J. Zhang, B. Ren, and Z. Wang, in Proceedings of 25th International Conference on Thermoelectrics (2006), p. 382 .

${ }^{25}$ R. F. Brebick and E. Gubner, J. Chem. Phys. 36, 1283 (1962).

${ }^{26}$ T. Su, X. Jia, H. Ma, J. Guo, Y. Jiang, N. Dong, L. Deng, X. Zhao, T. Zhu, and C. Wei, J. Alloys Compd. 468, 410 (2009).

${ }^{27}$ H. Wang, Y. Pei, A. D. LaLonde, and G. J. Snyder, Proc. Natl. Acad. Sci. 109, 9705 (2012).

${ }^{28}$ M. Orihashi, Y. Noda, L. Chen, and T. Hirai, Mater. Trans. 41, 1282 (2000).

${ }^{29}$ H. Wang, A. D. LaLonde, Y. Pei, and G. J. Snyder, Adv. Funct. Mater. 23, 1586 (2013)

${ }^{30}$ H. Xie, H. Wang, C. Fu, Y. Liu, G. J. Snyder, X. Zhao, and T. Zhu, Sci. Rep. 4, 6888 (2014). 